\title{
Applications of the fourth-generation multi- theory model (MTM) of health behavior change to obesogenic behaviors in college students
}

\begin{abstract}
Obesity is a public health crisis that has reached pandemic proportions. It has multifactorial etiology and multiple negative physical and psychological consequences. Controlling the problem by altering obesogenic behaviors among college students is especially important because there is growing prevalence in this subgroup, there are long term effects for this subgroup, they are in formative years for obesogenic behaviors, and these behaviors are widely prevalent in this subgroup. The multi-theory model (MTM) of health behavior change is a new fourth-generation behavioral theory that has been applied to study obesogenic behaviors among college students. The purpose of this review was to examine the robustness and utility of MTM in designing efficacious and effective interventions to address obesogenic behaviors among US college students. A total of five studies published in MEDLINE, CINAHL, or ERIC met the inclusion criteria.The mean adjusted $\mathrm{R}^{2}$ for the initiation model based on the five studies was 0.38 (s.d. 0.15) and the mean adjusted $\mathrm{R}^{2}$ for the sustenance model was 0.34 (s.d. 0.14). The construct of behavioral confidence in the initiation model and the construct of emotional transformation in the sustenance model were significant in all five studies. MTM offers a feasible and practical framework for designing health promotion interventions for college students to address obesogenic behaviors.
\end{abstract}

Keywords: obesogenic behaviors, heart disease, hypertension, adulthood
Volume 10 Issue 3 - 2020

\author{
Manoj Sharma \\ Behavioral and Environmental Health, School of Public Health, \\ USA
}

Correspondence: Manoj Sharma, Behavioral and Environmental Health, School of Public Health, Jackson State University, 350 W. Woodrow Wilson Drive, USA, Email manoj.sharma@jsums.edu

Received: June 07, 2020 | Published: June 23, 2020
Abbreviations: CARDIA, coronary artery risk development in young adults; MTM, multi-theory model

\section{Introduction}

Obesity is a serious public health problem in the United States and worldwide. Obesity has been labeled as a pandemic with an increase in its global prevalence among adults over the last three decades by $27.5 \% .{ }^{1}$ Overweight and obesity are associated with several negative outcomes such as Type 2 diabetes, heart disease, hypertension, cancer, and osteoarthritis. ${ }^{2}$ Besides contributing to physical ailments, being overweight and obese also causes negative mental sequelae such as distress, depression, low self-esteem, poor body image, eating disorders (bulimia and anorexia nervosa), and poor overall quality of life. ${ }^{3}$ The causation of obesity is multifactorial with genetic, physiological, behavioral, socioeconomic, cultural, and societal factors playing a role. ${ }^{4}$ Among these factors, obesogenic behaviors are most important because these are modifiable by implementing health promotion interventions that promote behavior change.

College students are an important subgroup when it comes to addressing obesogenic behaviors. Data from two representative surveys involving 24,613 American college students found an increasing trend of overweight and obesity over time and found it to be higher among African Americans, males, and among lower socioeconomic stratum. ${ }^{5}$ A survey at a Midwestern US University found the prevalence of being overweight or obese among college students to be $27.9 \% .{ }^{6}$ So the first reason for focusing on college students is the growing prevalence of overweight and obesity. The second reason for focusing on college students is the long term consequences that ensue from being overweight and obese at this age.Based on Coronary Artery Risk Development in Young Adults
(CARDIA) (a biracial cohort study from four cities in the US) data it was found that overweight and obesity in young adulthood were related to poorer health-related quality of life 20 years later. ${ }^{7}$ The third reason for focusing on college students is because some of the obesogenic behaviors including physical activity, dietary habits, drinking water instead of sugar-sweetened beverages, and sleep patterns are getting formed during this time..$^{8-10}$ The final reason for focusing on college students is that obesogenic behaviors are widely prevalent among this age group. According to the American College Health Association's national survey done in 2018 , it was found that only $42.6 \%$ of college students met the recommended physical activity guidelines, $24 \%$ reported sleep problems, and the majority were not consuming five or more servings of fruits and vegetables. ${ }^{11}$ Further, being overweight and obese has also been found to be associated with poorer academic achievement, depression, and using diet aids for weight loss. ${ }^{6}$ In a study done with college students, it was found that sitting more than 6 hours per day of sedentary behavior was prevalent in $69 \%$ of females and $46 \%$ of males. ${ }^{12}$

To address obesogenic behaviors among college students a number of health promotion interventions focusing on health behavior change have been designed and evaluated in recent years. More recently, fourth-generation multi-theory models have become popular in health promotion literature for health behavior change. ${ }^{13}$ One such model is the multi-theory model (MTM) of health behavior change that originated in 2015..$^{14,15}$ MTM bisects the behavior change into initiation and sustenance (maintenance). Three constructs namely participatory dialogue in which the individual must be convinced that advantages of behavior change are greater than disadvantages, behavioral confidence, and changes in the physical environment shape the initiation or start of the behavior change.Also, three constructs, namely emotional transformation, practice for change, and changes in 
the social environment foster the maintenance of the behavior change. It is in this backdrop that the purpose of this study was to review the applications of this contemporary, fourth-generation multi-theory model (MTM) of health behavior change in understanding obesogenic behaviors among college students. It was envisaged that based on this review, recommendations for developing interventions to address obesogenic behaviors among college students could be formulated.

\section{Methods}

In completing this study a literature review was conducted in MEDLINE (PubMed), CINAHL, and ERIC for locating all published studies based on the multi-theory model (MTM) of health behavior change. The inclusion criteria for included studies were (1) published in the above databases; (2) involving US college students; (3) explicit use of the multi-theory model (MTM) of health behavior change; and (4) focusing on obesogenic behaviors that included physical inactivity (sedentary lifestyle), consuming sugar-sweetened beverages, not eating recommended cups of fruits and vegetables, eating large portion sizes, and indulging in inadequate sleep. The exclusion criteria were: (1) articles not published in the above databases; (2) articles published in the gray literature; (3) published abstracts only; and (4) review or descriptive articles.

\section{Results}

A total of five studies met the inclusion criteria. These studies are summarized in Table 1 in chronological order by study/year/location, the focus of behavior change, sample size, the research design used, significant constructs of MTM, and adjusted $\mathrm{R}^{2}$ found in each study. The mean adjusted $\mathrm{R}^{2}$ for the initiation model based on the five studies was 0.38 (s.d. 0.15) and the mean adjusted $\mathrm{R}^{2}$ for the sustenance model based on the five studies was 0.34 (s.d. 0.14). The construct of behavioral confidence in the initiation model and the construct of emotional transformation in the sustenance model were significant in all five studies.

Table I Summary of studies $(n=5)$ for obesogenic behaviors among US college students based on multi-theory model (MTM) of health behavior change

\begin{tabular}{|c|c|c|c|c|c|}
\hline Study/year/Location & Focus of behavior change & Sample size & Design & Significant constructs of MTM & Adjusted $\mathbf{R}^{2}$ \\
\hline \multirow[t]{8}{*}{ Nahar et al., ${ }^{16}$ Mississippi } & $\begin{array}{l}\text { Physical activity from } \\
\text { sedentary behavior }\end{array}$ & $n=|4|$ & $\begin{array}{l}\text { Cross- } \\
\text { sectional }\end{array}$ & Initiation: & Initiation: 0.26 \\
\hline & & & & Participatory dialogue $(p=0.018)$ & Sustenance: 0.30 \\
\hline & & & & \multicolumn{2}{|l|}{ Behavioral confidence $(p<0.001)$} \\
\hline & & & & \multicolumn{2}{|c|}{ Changes in the physical environment $(p=0.008)$} \\
\hline & & & & \multicolumn{2}{|l|}{ Sustenance: } \\
\hline & & & & \multicolumn{2}{|l|}{ Emotional transformation $(\mathrm{p}=0.019)$} \\
\hline & & & & \multicolumn{2}{|l|}{ Practice for change $(p<0.00 I)$} \\
\hline & & & & \multicolumn{2}{|c|}{ Changes in the social environment $(p=0.022)$} \\
\hline \multirow[t]{6}{*}{ Sharma et al., ${ }^{17}$ Mississippi } & $\begin{array}{l}\text { Small portion size from large } \\
\text { portion size }\end{array}$ & $n=135$ & $\begin{array}{l}\text { Cross- } \\
\text { sectional }\end{array}$ & Initiation: & Initiation: 0.37 \\
\hline & & & & Participatory dialogue $(p=0.006)$ & Sustenance: 0.20 \\
\hline & & & & \multicolumn{2}{|l|}{ Behavioral confidence $(\mathrm{p}<0.00 \mathrm{I})$} \\
\hline & & & & \multicolumn{2}{|l|}{ Sustenance: } \\
\hline & & & & \multicolumn{2}{|l|}{ Emotional transformation $(p=0.001)$} \\
\hline & & & & \multicolumn{2}{|c|}{ Changes in the social environment $(p=0.033)$} \\
\hline \multirow[t]{6}{*}{$\begin{array}{l}\text { Knowlden et al., }{ }^{18} \\
\text { Alabama }\end{array}$} & $\begin{array}{l}\text { Adequate sleep from } \\
\text { inadequate sleep }\end{array}$ & $n=|5|$ & $\begin{array}{l}\text { Cross- } \\
\text { sectional }\end{array}$ & Initiation: & Initiation: 0.24 \\
\hline & & & & Behavioral confidence $(\mathrm{p}<0.00 \mathrm{I})$ & Sustenance: 0.34 \\
\hline & & & & \multicolumn{2}{|l|}{ Sustenance: } \\
\hline & & & & \multicolumn{2}{|l|}{ Emotional transformation $(p=0.00 \mathrm{I})$} \\
\hline & & & & \multicolumn{2}{|l|}{ Practice for change $(p<0.00 \mathrm{I})$} \\
\hline & & & & \multicolumn{2}{|c|}{ Changes in the social environment $(p=0.023)$} \\
\hline
\end{tabular}


Table Continued..

\begin{tabular}{|c|c|c|c|c|c|}
\hline Study/year/Location & Focus of behavior change & Sample size & Design & Significant constructs of MTM & Adjusted $\mathbf{R}^{2}$ \\
\hline \multirow[t]{2}{*}{ Sharma et al., ${ }^{19}$ Mississippi } & $\begin{array}{l}\text { Water consumption from } \\
\text { sugar-sweetened beverage } \\
\text { consumption }\end{array}$ & $n=174$ & $\begin{array}{l}\text { Cross- } \\
\text { sectional }\end{array}$ & Initiation: & Initiation: 0.62 \\
\hline & & & & $\begin{array}{l}\text { Behavioral confidence }(p=0.00 \mathrm{I}) \\
\text { Changes in the physical environment } \\
\text { Sustenance: } \\
\text { Emotional transformation }(p=0.00 \mathrm{I}) \\
\text { Practice for change }(p=0.00 \mathrm{I})\end{array}$ & $\begin{array}{l}\text { Sustenance: } 0.58 \\
(p=0.001)\end{array}$ \\
\hline \multirow[t]{7}{*}{ Sharma et al., ${ }^{20}$ Mississippi } & $\begin{array}{l}\text { Eating recommended cups of } \\
\text { fruits and vegetables from not } \\
\text { eating enough }\end{array}$ & $\mathrm{n}=175$ & $\begin{array}{l}\text { Cross- } \\
\text { sectional }\end{array}$ & Initiation: & Initiation: 0.40 \\
\hline & & & & Behavioral confidence $(p<0.00 I)$ & Sustenance:0.30 \\
\hline & & & & Changes in the physical environment & $(p=0.001)$ \\
\hline & & & & Sustenance: & \\
\hline & & & & Emotional transformation $(p=0.03)$ & \\
\hline & & & & Practice for change $(p<0.00 \mathrm{I})$ & \\
\hline & & & & Changes in the social environment & $=0.025)$ \\
\hline
\end{tabular}

\section{Discussion}

This review aimed to examine all studies conducted regarding the comprehension of the determinants of obesogenic behaviors among college students based on the multi-theory model (MTM) of health behavior change. Based on the five studies found in the literature targeting physical inactivity (sedentary behavior), eating large portion sizes, indulging in inadequate sleep, consuming sugar-sweetened beverages, and not eating the recommended five cups of fruits and vegetables it was found that the MTM and its components of initiation and sustenance provided statistically significant constructs that contributed substantially to the proportion of variance in the intention for behavior changes as the dependent variable. The adjusted $R^{2}$ is the percentage of variation explained by the independent variables that affect the dependent variable and is a measure of the effect size. ${ }^{21}$ The mean adjusted $\mathrm{R}^{2}$ from the five studies was 0.38 for the initiation model and 0.34 for the sustenance model which is quite substantial for behavioral sciences according to Cohen's criterion of greater than 0.26 as being substantial. ${ }^{22}$ This lends credence to the utility of MTM in designing pragmatic and effective interventions to address obesogenic behaviors among US college students.

In terms of the constructs of the MTM, it was found that for initiating or starting change with regard to any obesogenic behavior, behavioral confidence was paramount and came out to be significant in all the studies.This construct is somewhat similar to selfefficacy ${ }^{23,24}$ but is also somewhat different from it. The similarity is in terms of mastery of this confidence through practicing in small steps but the difference is that the source of the confidence can emanate from sources other than self (such as faith in Almighty or faith on a trusted family member and so on) and it is futuristic as opposed to being focused on the present. In designing interventions for college students pertaining to altering obesogenic behaviors efforts must be made to modify their behavioral confidence.This can be easily linked to technological innovations such as mobile apps that provide mastery of steps of behavior change. In hybrid and face-to-face interventions, and even in pure web-based interventions, sources of behavioral confidence should be explored with the participants in helping them identify multiple sources of behavioral confidence and building it sequentially over time.

In the initiation model, the participatory dialogue construct was only significant with regard to changing physical inactivity behavior to physically active behavior and consuming smaller portion sizes from large portion sizes.It was not significant for changing inadequate sleep behavior or drinking water instead of sugar-sweetened beverages or consuming five or more cups of fruits and vegetables every day. This could be because the former behaviors are more overtly linked to physical appearance and college students may be more receptive to that aspect in appreciating the advantages over disadvantages of those behaviors. Such an appeal should be used in designing interventions for these behaviors. For other behaviors, qualitative approaches such as focus group discussions or semi-structured interviews with students should be conducted in identifying what aspects of the behavior change they find useful, and then accordingly those aspects should be built into the program.

In the initiation model, the construct of changes in the physical environment was significant for the behaviors of drinking water instead of sugar-sweetened beverages, consuming recommended levels of fruits and vegetables, and performing physical activity. The availability and accessibility of physical resources are important for these behaviors and should be identified at the family, organizational (university), and community levels. It is important to remove sugarsweetened beverages from our environment, have adequate access to inexpensive produce, and have playgrounds and gyms where physical 
activity can be performed.Such measures will require both policy level and societal efforts. The behaviors of sleep and portion size are more personal behaviors and perhaps changes in the physical environment are not that crucial. In the absence of adequate time and resources, these may not be prioritized in designing interventions addressing obesogenic behaviors among college students.

For maintaining the changes regarding all obesogenic behaviors the construct of emotional transformation stood out to be significant across all the studies. Work about emotional intelligence ${ }^{25,26}$ is becoming more and more important and contemporary theories of behavior change have not adequately recognized the value of this construct. It is very important not only in changing behaviors but also overall success in life that college students start embracing the tenets of this construct early on. It requires one to be cognizant of one's feelings especially negative ones and then transforming those into concrete and specific goals of behavior change. In interventions the principles for modifying this construct can be taught in all formats: face-to-face, hybrid, and online.For sustenance of obesogenic behavior change concerning the construct of practice for change, all behaviors except portion size behavior found the construct to be significant. It is important to constantly think of the behavior change through reminders and in contemporary interventions, this is being done through text messaging. ${ }^{27}$ However, it also requires motivation on part of the individual making the behavior change to be reflective continually and such motivation can be fostered in health promotion interventions.

Finally, for sustaining obesogenic behaviors, the construct of changes in the social environment was found to be significant for all behaviors except the consumption of water instead of sugarsweetened beverages. The consumption of water is a very personal behavior and perhaps the influence of social support is not that vital. However, for all other behaviors building social support either natural through family and friends or artificial through health professionals is important for behavior change and must be built into programs targeting obesogenic behaviors among college students.

\section{Limitations of the studies reviewed}

The studies reviewed in this article had some limitations.First, the studies have been confined to single University settings in the Southern United States. Thus, the results may not be generalizable to all US college students. Future studies must be conducted with larger representative samples of US college students. Second, the design used in all studies was cross-sectional.This type of design is a snapshot in time and does not provide definitive evidence for time sequence which is important to establish causality. Future studies should utilize longitudinal and experimental designs.Third, the studies utilized only self-report and the actual behaviors were not observed or measured. This can lead to measurement bias in the results.Future studies must use more objective measures to document behavior change. Finally, none of the studies conducted a test-retest reliability assessment on the tools that were used.This would be a potential hindrance in utilizing these tools in conducting experimental studies because there would be a possibility for measurement bias. Future studies should establish the stability of the instruments used in these studies.

\section{Limitations of this review}

This review also had some limitations. First, the number of studies was very small. But the model is quite new and upcoming. It is envisaged that in the forthcoming years more data will be available and the review can be expanded. Second, the review was narrative.
While a mean effect size in the form of mean adjusted $\mathrm{R}^{2}$ was calculated in this study but the outcome measures were different so it is only a crude estimation of the effect size. When more studies with the same outcome variables are available, systematic meta-analyses can provide more refined estimates of the effect sizes. Third, the study was confined to only US college students and other variants were not included some of which included dental students in India and veterinary students in the US. Finally, the review did not include gray literature or published abstracts at conferences and only included published studies which may have added to publication bias. ${ }^{28}$

\section{Conclusion}

MTM is a relatively new, fourth-generation theory in health behavior that incorporates effective elements from multiple theories. It was found to be both significant and contributed substantially to explaining obesogenic behaviors among US college students. MTM offers a feasible and practical framework for designing health promotion interventions for college students to address obesogenic behaviors.

\section{Acknowledgments}

None.

\section{Conflicts of interest}

The author declares that there is no conflict of interest.

\section{Funding}

None.

\section{References}

1. Ng M, Fleming T, Robinson M, et al. Global, regional, and national prevalence of overweight and obesity in children and adults during 19802013: a systematic analysis for the Global Burden of Disease Study 2013. Lancet. 2014;384(9945):766-781.

2. Meldrum DR, Morris MA, Gambone JC. Obesity pandemic: causes, consequences, and solutions-but do we have the will? Fertil Steril. 2017;107(4):833-839.

3. Chu DT, Minh Nguyet NT. An update on obesity: mental consequences and psychological interventions. Diabetes Metab Syndr. 2019;13(1):155160.

4. Apovian CM. Obesity: definition, comorbidities, causes, and burden. $A m$ J Manag Care. 2016;22(7 Suppl):s176-185.

5. Nelson TF, Gortmaker SL, Subramanian SV, et al. Disparities in overweight and obesity among US college students. Am J Health Behav. 2007;31(4):363-373.

6. Odlaug BL, Lust K, Wimmelmann CL, et al. Prevalence and correlates of being overweight or obese in college. Psychiatry Res. 2015;227(1):58-64.

7. Kozak AT, Daviglus ML, Chan C, et al. Relationship of body mass index in young adulthood and health-related quality of life two decades later: the Coronary Artery Risk Development in Young Adults study. Int J Obes. 2011;35(1):134-141.

8. Kozak AT, Pickett SM, Jarrett NL, et al. Project STARLIT: protocol of a longitudinal study of habitual sleep trajectories, weight gain, and obesity risk behaviors in college students. BMC Public Health. 2019;19(1):1720.

9. Deliens T, Clarys P, De Bourdeaudhuij I, et al. Correlates of university students' soft and energy drink consumption according to gender and residency. Nutrients. 2015;7(8):6550-6566. 
10. West DS, Bursac Z, Quimby D, et al. Self-reported sugar-sweetened beverage intake among college students. Obesity. 2006;14(10):18251831.

11. American College Health Association. American College Health Association-National College Health Assessment II: Reference Group Executive Summary Spring 2018. Silver Spring: American College Health Association; 2018.

12. Vainshelboim B, Brennan GM, LoRusso S, et al. Sedentary behavior and physiological health determinants in male and female college students. Physiol Behav. 2019;204:277-282.

13. Sharma M. Trends and prospects in public health education: a commentary. Social Behavior Research \& Health. 2017;1(2):67-72.

14. Sharma M. Multi-theory model (MTM) for health behavior change. WebmedCentral Behaviour:2015;6(9):WMC004982.

15. Sharma M. Theoretical foundations of health education and health promotion. 3rd ed. Burlington, MA: Jones and Bartlett Publishers; 2017.

16. Nahar VK, Sharma M, Catalano HP, et al. Testing multi-theory mode (MTM) in predicting initiation and sustenance of physical activity behavior among college students. Health Promot Perspect. 2016;6(2):5865

17. Sharma M, Catalano HP, Nahar VK, et al. Using multi-theory model to predict initiation and sustenance of small portion size consumption among college students. Health Promot Perspect. 2016;6(3):137-144.

18. Knowlden AP, Sharma M, Nahar VK. Using multi-theory model of health behavior change to predict adequate sleep behavior. Fam Community Health. 2017;40(1):56-61.
19. Sharma M, Catalano HP, Nahar VK, et al. Applying multi-theory model (MTM) of health behavior change to predict water consumption instead of sugar-sweetened beverages. J Res Health Sci. 2017;17(1):e00370.

20. Sharma M, Stephens PM, Nahar VK, et al. Using multi-theory model to predict initiation and sustenance of fruit and vegetable consumption among college students. J Am Osteopath Assoc. 2018;118(8):507-517.

21. Tabachnik BG, Fiddell LS. Using multivariate statistics. 7th ed. New York, Pearson; 2019.

22. Cohen J. Statistical power analysis for the behavioral sciences. 2nd ed. New York, Lawrence Erlbaum Associates; 1988.

23. Bandura A. Self-efficacy in changing societies. New York: Cambridge University Press; 1995.

24. Bandura A. Self-efficacy: The exercise of control. New York: WH Freeman; 1997.

25. Goleman D. Emotional intelligence. New York: Bantam; 1995.

26. Branscum P, Bhochhibhoya A, Sharma, M. The role of emotional intelligence in mental health and Type D personality among young adults. Int $Q$ Community Health Educ. 2013;34(4):351-365.

27. Hayes T, Sharma M, Shahbazi M, et al. The evaluation of a fourthgeneration multi-theory model (MTM) based intervention to initiate and sustain physical activity. Health Promot Perspect. 2019;9(1):13-23.

28. DeVito NJ, Goldacre B. Catalogue of bias: publication bias. BMJ Evid Based Med. 2019;24(2):53-54. 